\title{
Repercussões das politicas educacionais na organização escolar: o fator tempo entre a autonomia e a regulação
}

\author{
Repercussions of educational policies on school organization: \\ the time factor between autonomy and regulation \\ Repercusiones de las políticas educativas en la organización escolar: \\ el factor tiempo entre la autonomía y la regulación
}

ALICE MIRIAM HAPP BOTLER

\begin{abstract}
Resumo: $\mathrm{O}$ artigo aborda o conflito existente entre as políticas educacionais e sua implementação nas escolas, haja vista a contradição entre a autonomia outorgada e a regulação. Considera que a escola é uma organização formal, instituída e instituinte, e desenvolve comportamento organizacional e valorativo que revela seu projeto político-pedagógico com racionalidade própria. O estudo de caso de tipo etnográfico numa escola pública auxilia a entender como esta contradição emerge na prática. Observa-se que a falta de tempo para o diálogo opõe-se aos objetivos das metas educacionais, o que limita mas não elimina o potencial crítico-argumentativo necessário à sua auto-proposição e auto-regulação.
\end{abstract}

Palavras chave: Organização escolar; gestão da educação; tempo, racionalidade instrumental; racionalidade comunicativa.

Abstract: The article discusses the conflict between educational policy and its implementation in schools, given the contradiction between the granted autonomy and regulation. It considers that the school is a formal organization, established and instituting, and develops organizational and evaluative behavior that reveals a political-pedagogical project with its own rationality. The ethnographic case study in a public school helps to understand how this contradiction emerges in practice. It is observed that the lack of time for dialogue is opposed to the objectives of educational goals, which limits but does not eliminate the critical and argumentative potential necessary for its self-proposition and self-regulation.

Keywords: School organization; management education; time; instrumental rationality; communicative rationality.

Resumen: El artículo aborda el conflicto entre la política educativa y su aplicación en las escuelas, dada la contradicción entre la autonomía concedida y la regulación. Considera que la escuela es una organización formal, establecida y instituyente y desarrolla el comportamiento organizacional y de evaluación que revela su proyecto político-pedagógico con su propia racionalidad. El estudio de caso etnográfico en una escuela pública ayuda a entender cómo esta contradicción surge en la práctica. Se observa que la falta de tiempo para el diálogo se opone a los objetivos de las metas educativas, lo que limita, pero no elimina el potencial crítico y argumentativo necesario para su auto-propuesta y autorregulación. 
Palabras clave: Organización escolar; gestión de la educación; tiempo; de racionalidad instrumental,;racionalidad comunicativa.

\section{INTRODUÇÃO}

Criada e estruturada com base em determinações do sistema educacional nacional, a escola é vista como uma organização formal, desde que seu funcionamento segue regras definidas, como a legislação educacional, as regulamentações e dispositivos que dão organicidade às leis. $\mathrm{O}$ que discutimos neste artigo é o conflito existente entre a regulamentação educacional e a real possibilidade de sua implementação por parte das unidades do sistema - as escolas -, visto que há contradições entre a regulamentação e a sua implementação na prática. Em outras palavras, a escola é instituída do ponto de vista do sistema educacional macro-político e, do ponto de vista micro-político, é instituinte. Como mediação entre estes dois níveis resulta um comportamento organizacional e valorativo que revela o próprio projeto político-pedagógico da Escola (CORTINA,1988; NÓVOA, 1992). Este conflito nos interessa aprofundar num contexto em que o Brasil faz fortes investimentos em educação, mas apresenta ainda fracos resultados, o que, inclusive, pode ser constatado em recente anúncio da presidente Dilma Roussef ao tratar do lema da gestão 2015: "Brasil: Pátria Educadora".

Assim, por exemplo, conforme o modelo democrático, a escola tem autonomia financeira ao mesmo tempo em que o sistema precisa de mecanismos de regulação e fiscalização sobre a aplicação dos recursos públicos. A regulação e a fiscalização geram burocracia, o que termina limitando a autonomia financeira na realidade escolar, visto que há dissociação entre o prazo de entrega do planejamento escolar, a análise dos planos, a distribuição de recursos entre as prioridades do sistema, o envio e a aplicação de verbas. O que ocorre é que, na prática, as demandas da Escola por recursos financeiros referem-se às necessidades do trabalho pedagógico desenvolvido durante o ano letivo e as verbas chegam, freqüentemente, depois do período previsto para sua aplicação.

Neste artigo abordamos um recorte de pesquisa que apresenta o conflito gerado considerando a relação existente entre a burocracia necessária ao sistema e o fator tempo, argumento frequentemente considerado como elemento limitante à realização efetiva das determinações sistêmicas, ou seja, o sistema prega autonomia financeira e, ao mesmo tempo, limita burocraticamente a possibilidade de autonomização.

Para tratar deste tema, problematizamos as racionalidades que perpassam a gestão da educação e da escola e, em seguida, apresentamos alguns 
resultados de pesquisa que focalizou as repercussões das políticas educacionais na gestão da escola, em que procura-se destacar a racionalidade cognitivoinstrumental da racionalidade comunicativa, via estudo etnográfico em que coletamos informações por meio de processo intensivo de observações, entrevistas e conversas informais, cujos sujeitos aparecem aqui identificados por iniciais de seus respectivos segmentos da escola: D para diretora, $\mathrm{P}$ para professor, $\mathrm{E}$ para estagiário, CTP para coordenação técnico-pedagógica, M para mãe de aluno. Da mesma forma, designamos a escola campo de pesquisa simplesmente de Escola. Ao final, tecemos considerações a respeito dos limites e possibilidades de desenvolvimento do potencial crítico-argumentativo próprio à auto-regulação da escola, como reflexo das determinações sistemicas.

\section{A GESTÃO DA EDUCAÇÃO E AS DIVERSAS RACIONALIDADES}

$\mathrm{O}$ argumento central aqui apresentado pauta-se na ideia de que o sistema educacional é perpassado por distintas lógicas e estratégias que são guiadas por diferentes interesses e poderes. Autores como Friedberg (1993), Estêvão (1998), Derouet (1998) apontam para as relações entre o ator e o sistema, tratando de mundos diversos que guiam lógicas de ação diferentes: o mundo mercantil, o mundo industrial, o mundo doméstico, o mundo cívico, o mundo da inspiração, o mundo da opinião. Enfocam principalmente a ação, e não apenas a organização, considerando a lógica estratégica dos atores, em contraposição à lógica do sistema, da organização. São mundos diferentes que induzem lógicas argumentativas diferentes.

Numa organização, por exemplo, quando não se chega a um acordo, há necessidade de avançar numa negociação, na busca de uma "civilidade mínima". A existência da negociação exige o reconhecimento e a mobilização de uma lógica em que os atores buscam entrar em acordo para resolver os conflitos. Com isto entende-se que a organização é também perpassada por distintas racionalidades de diferentes mundos, bem como os indivíduos circulam em diversos desses mundos.

A ação organizacional inclui estas diversas dimensões ou dinâmicas internas, do acordo, do conflito, da negociação, do compromisso, da disputa, noções que indicam racionalidades diferentes e que geram princípios argumentativos diferentes. Os atores são como vários mundos, com lógicas próprias, com conceitos diferentes. Essas racionalidades atravessam qualquer mundo, inclusive a escola, trazendo, por exemplo, a exigência da negociação. Quando a negociação não existe, pode significar que uma das lógicas pode estar sendo predominante, bem como que outras estejam sendo tolerantes. 
Por isso, os problemas da organização escolar podem estar sendo derivados justamente das diferentes lógicas ou racionalidades. Assim, por exemplo, uma lógica individualista pode estar guiando, de modo geral, o mundo da escola e até predominando sobre outras lógicas, como as do compromisso e da responsabilidade, o que não implica na exclusão de outras predominantes no sistema educacional, como a formal-burocrática.

Habermas discute o conceito de racionalidade a partir da idéia da "razão situada na historia e na sociedade, configurada no entendimento lingüístico" (PIZZI, 1994), extrapolando os limites do sujeito monológico, privilegiando o sujeito da comunicação situado no Mundo da Vida, ou seja, entende que uma racionalidade deve resguardar "a pretensão intersubjetiva de validade que tenha o mesmo significado tanto para o observador ou destinatário como para o sujeito agente.”(HABERMAS, 1987).

Habermas reformulou o conceito de racionalização de Weber, que afirmava que a ação racional seria dirigida a fins e exercício de controle e, por isso mesmo, a racionalização das relações vitais equivaleria à institucionalização de uma dominação e indicaria uma combinação entre a ação instrumental, que se orienta por regras técnicas que se apóiam no saber empírico, e um comportamento da escolha racional, que se orienta por estratégias que se baseiam num saber analítico, implicando deduções de regras de preferência (sistemas de valores). Para o autor, enquanto a ação instrumental organiza meios que são adequados ou inadequados segundo critérios de um controle eficiente de realidade, a ação estratégica depende apenas de uma valoração correta de possíveis alternativas de comportamento, que só pode obter-se de uma dedução feita com o auxílio de valores e máximas. Neste sentido, Habermas (1968) distingue a racionalidade cognitivo-instrumental da racionalidade comunicativa (substantiva).

Ação comunicativa é uma interação simbolicamente mediada, que se orienta segundo normas que definem as expectativas recíprocas de comportamento. A racionalidade da ação comunicativa confronta-se com a racionalidade da ação instrumental e estratégica e aí entram em crise os modelos da sociedade tradicional e as formas de legitimação da dominação.

Habermas afirma que a racionalização progressiva da sociedade depende da institucionalização do progresso científico e técnico. Na medida em que a técnica e a ciência perpassam as esferas institucionais da sociedade, transformam as próprias instituições, criando novas legitimações ou novas lógicas. A racionalização tende ao deslocamento da orientação da ação voltada para valores racionais para a ação puramente instrumental. Em outras palavras, "racionalização significa, em primeiro lugar, a ampliação das esferas sociais, que ficam submetidas aos critérios de decisão racional” (HABERMAS, 1968, p.45). 
Conforme Pizzi, o conceito de razão de Habermas passa a incluir "além do argumento cognitivo e instrumental, o procedimento lingüístico e a argumentação discursiva" (1994, p.45).

As normas sociais são reforçadas por sanções, mas a validade das normas sociais só se funda na intersubjetividade do acordo acerca de intenções e só é assegurada pelo reconhecimento geral das obrigações. As regras apreendidas da ação racional equipam-nos com a disciplina de habilidades. As normas internalizadas dotam-nos com estruturas da personalidade. As habilidades capacitam-nos para resolver problemas e as motivações permitem-nos praticar a conformidade com as normas. (HABERMAS, 1968, p.58).

Assim, as organizações podem ser vistas como subsistemas que são perpassados por lógicas externas (como a do Estado, da economia,...), principalmente fundamentadas numa razão que é instrumental, bem como por lógicas que lhe são internas (como seu contexto de interação, de comunicação, de interpretação,...), que podem ser mais embasadas numa razão comunicativa, mas também são perpassadas pela racionalidade instrumental. As soluções ou respostas encontradas para os problemas postos são soluções aceitáveis para todas as partes, com sentido de equilíbrio dinâmico. (BOTLER, 2004).

Habermas(1968) vê duas tendências na racionalização, onde uma corresponde à resistência à outra, onde legitimações enfraquecidas são substituídas por outras novas que, por seu turno, nascem da crítica à dogmática das interpretações tradicionais do mundo e pretendem possuir um caráter científico e que, por outro lado, mantêm funções legitimadoras e subtraem as relações de poder existentes tanto à análise como à consciência pública. Assim surgem as ideologias, que substituem as legitimações tradicionais da dominação, ao apresentarem-se com a pretensão à ciência moderna (novas verdades com caráter instituinte) e ao justificarem-se a partir da crítica às ideologias.

Esta discussão conceitual nos auxilia a esclarecer as diferentes lógicas que regem as organizações sociais na prática, num misto entre uma racionalidade burocratizante (na perspectiva weberiana) e uma racionalidade crítico-argumentativa (na perspectiva habermasiana). O argumento se justifica por considerarmos que a escola é instituída por um sistema caracterizado por uma lógica macropolítica, ao mesmo tempo em que não pode se despojar de sua própria interpretação normativa e processamento interno das regras às quais se submete, desenvolvendo internamente sua própria lógica, o que implica em conflitos.

Queremos dizer com isto que as sociedades modernas encontramse em um estado de desenvolvimento das forças produtivas que torna permanente a expansão dos subsistemas de ação racional teleológica. 
As culturas tecnologicamente mais avançadas legitimam a dominação mediante interpretações do mundo proporcionando respostas aos problemas relativos à convivência social e à história da vida individual.

Isto auxilia a explicar a recente tendência das políticas educacionais à substituição do modelo da centralização administrativa em nome da racionalidade de meios (vigente até meados dos anos 80), por um modelo da descentralização apresentado pelas políticas contemporâneas, orientando o sistema educacional para uma nova forma de legitimação da dominação, em nome da democratização da sociedade. Substituição de legitimação não implica em mudança na perspectiva que sustenta a racionalidade e as normas sociais veiculadas num novo contexto histórico. A este novo formato podemos chamar de direção democrática, atribuído pelo sistema educacional como caminho a ser perseguido, mais do que desenvolvido internamente pela organização escolar.

Estêvão(1998) explica que em países como Portugal, a direção democrática é dada pelo órgão responsável pela definição das orientações, políticas e valores da escola e, por isso mesmo, respeita o critério da democraticidade. Diferentemente, a noção de gestão refere-se ao órgão de execução das orientações emanadas do 'órgão de direção' e, neste sentido, respeita os critérios de eficiência e de eficácia. O que acontece, é que o órgão de direção esteve muito tempo fora da escola (no Ministério da Educação) e a gestão democrática esteve quase confinada aos ditames do Ministério. Neste sentido, a direção era heterocéfala e as normas geradas a partir de fora da organização.

A direção democrática tende a propor caminhos que motivem a organização escolar, mas que não necessariamente chegam à mobilização característica da gestão democrática endogenamente constituída. Por isso mesmo, seu perfil se assemelha mais com o de uma organização burocrática, seguindo a lógica da racionalização e não de uma ražão, propriamente dita.

Nestes termos, poderíamos estabelecer associação com a análise da organização escolar a partir do modelo díptico proposto por Lima (2002), quando explica a interface entre o modo de funcionamento da organização escolar, que flui entre uma burocracia racional e uma anarquia organizada, ou ainda, um aprofundamento do modelo políptico proposto por Estêvão (1998) que aponta para uma análise multifocalizada em termos de proposição organizacional.

As normas sociais e sistemicas dirigem o modo como os resultados (castigos e recompensas) devem ser distribuídos, os processos utilizados para tomar decisões acerca dessa distribuição e o modo como as pessoas são tratadas interpessoalmente. Neste sentido, podem funcionar como controle social relativamente ao uso (e abuso) de poder e como parte da retórica social, para 
justificar um uso questionável do poder em muitas decisões ligadas à gestão, mais do que como novos e substantivos valores.

Esta multiplicidade de elementos que intervêm na constituição, formação e dinâmica das organizações torna seu estudo muito complexo e gera confusão entre os sentidos atribuídos a normas e valores, seja como racionalidade instrumental, seja como racionalidade substantiva. Um dos elementos mais importantes neste debate é a capacidade que as pessoas têm para tomar decisões, considerada em função de papéis atribuídos e assumidos, e que condiciona a dinâmica de participação nas organizações. Participação leva a um engajamento e responsabilização (decisão racional) no contexto da organização social. A decisão é parte do processo, mas não é a decisão que dá o sentido às ações.

As decisões são, portanto, tomadas em função da racionalidade organizacional e da interação social, conduzindo à normatização institucional, no sentido da racionalização ou da razão.

Estes aspectos nos conduzem a compreender como ocorre a constituição de normas no interior das escolas, a partir da dupla determinação - regulamentar do sistema e interpretativa da própria escola. O resultado em termos de ações pode reverberar sob formato de cumprimento burocrático às normas do sistema, mas também como construção endógena da escola sob forma de alternativas de cumprimento regulamentar e desenvolvimento da autonomia. A seguir apresentamos um recorte dos dados da pesquisa que denota esta dupla determinação, a partir da análise do fator tempo como aspecto da organização escolar numa perspectiva transformadora.

\section{O FATOR TEMPO ENTRE OS LIMITES NORMATIVOS E A RACIONALIDADE COMUNICATIVA}

Realizamos uma pesquisa do tipo estudo de caso de cunho etnográfico, numa escola pública municipal de Recife, Pernambuco, tendo como abordagem complementar a observação participante (VIANNA, 2003). Procuramos conhecer os hábitos de vida e os diversos pontos de vista da organização escolar a partir da análise do modelo adotado pelas políticas educacionais, centrado na democratização e descentralização, que ainda guarda resquícios do modelo burocrático, configurando um formato de gestão organizacional numa perspectiva domesticadora. Apontamos como possibilidade emancipadora outro formato em processo de construção, estimulado a partir das lacunas apresentadas no modelo democrático, que configuramos sob inspiração habermasiana.

Neste sentido, a analise contribui com o debate sociológico e educacional, especialmente sob dois aspectos. Um deles, que aprofunda a discussão a respeito 
da democracia na modernidade sob aparência de modelo novo, sob enfoque conservador (SANTOS, 2001). Outro, apresentando indicadores de uma atividade organizacional escolar que permite vislumbrar uma prática social sob enfoque emancipador (HABERMAS, 1987). Um destes indicadores foi o fator tempo, como veremos a seguir.

O fator tempo nos chamou a atenção, desde que nossa preocupação centrava-se na possibilidade do estabelecimento de bases dialógicas argumentativas na dinâmica escolar como pressuposto para o estabelecimento de uma gestão democrática coletivamente construída. Consideramos inicialmente que a disponibilidade de tempo para diálogo reflexivo estaria relacionada às possibilidades de ampliar os fundamentos para a construção do consenso organizacional.

Assim, a falta de tempo para o diálogo ou a lentidão dos processos (que desagrada aos anseios da clientela escolar por objetivos imediatos) supostamente limitariam seu potencial crítico-argumentativo. De fato, observamos em diversas ocasiões formais ou informais na escola analisada, as possibilidades e os limites impostos pela falta de tempo ou morosidade nos processos organizacionais.

A relação tempo e potencial crítico-argumentativo foi também relacionada ao reconhecimento ou identificação da liderança, desde que alguns sujeitos entrevistados reconheceram que, apesar da diretora, a Escola oferece bom ensino.

Ressaltamos o fator tempo também (como sendo limitador ou norteador) quando observamos a dinâmica das conversas que tivemos com o corpo técnicopedagógico. Em nossa primeira visita à Escola conversamos com a diretora, em pé, no corredor, à porta da sala da direção, assim como ocorreu em quase todas as outras conversas que tivemos com ela ao longo dos tres meses de observação intensiva, tendo sido interrompidas por diversas vezes, ora por professores, ora por funcionários ou ainda alunos, por motivos diversos como solicitação de material, consulta sobre procedimentos, informações. Apenas em uma ocasião, dia em que não havia alunos na Escola, pudemos nos deter numa conversa mais prolongada e detalhada, sentadas numa sala de aula quase sem interrupções.

Nossa experiência com a vice-diretora foi semelhante, visto que não conseguimos uma entrevista, apenas diálogos breves e súbitos em meio à dinâmica das atividades. De fato, no período em que estivemos na Escola, ela foi convidada para desempenhar alguma atividade na Secretaria Municipal de Educação e, portanto, passava por um momento de transição funcional. Mesmo assim, tivemos sua presença na Escola durante, pelo menos, um mês, sempre com pouco tempo. 
A coordenadora pedagógica nos concedeu uma longa entrevista num dia em que os alunos haviam retornado para suas casas em função da falta de água na Escola. Ela não esteve ao nosso alcance nem para conversas rápidas informais em momento algum, a não ser neste dia, embora estivesse bastante presente na Escola, onde pudemos observar suas considerações em interrelação com professores, educadores itinerantes e de apoio da equipe da Secretaria de Educação, em reuniões. Nas palavras da coordenadora pedagógica, o papel da liderança é reconhecido e valorizado como fator identificador, assim expresso: "A felicidade foi encontrar pessoas como Diretora e Vice-Diretora, que pensam como eu e a gente pensa no coletivo e se divide."(CTP).

A questão do tempo aparece aí como elemento que não inibe o trabalho integrado da equipe pedagógica, desde que as pessoas que a compõem apresentem pleno entrosamento e sintonia, dividindo tarefas e mesclando papéis nos momentos em que isto se torna necessário. O tempo, então, interfere mas não é considerado como elemento limitador ao bom desempenho do trabalho escolar numa perspectiva coletivista.

Outro fator considerado como problemático em termos da organização escolar instituída e que poderia justificar a falta de tempo para uma melhor articulação com o projeto pedagógico da Escola, diz respeito à alternância sistêmica de pessoas na escola. A crescente política de reduzir a contratação de pessoal para os serviços públicos aumenta o número de professores não permanentes em regime de "mini-contrato" e um exército de estagiários de nivel médio, que parece dificultar o aprendizado coletivo. No período em que estivemos observando, a secretaria da Escola forneceu os seguintes dados: havia 24 estagiários distribuídos entre os serviços de secretaria, sala de aula e informática, além de 06 professores com contrato provisório. Este quantitativo equivale a mais da metade dos profissionais em regime de contrato permanente. O quantitativo de pessoal de sala de aula, especificamente, demonstra que para 28 professores efetivos distribuídos nos diversos níveis de ensino, a Escola conta com mais 06 professores em mini-contrato e sete estagiários de sala de aula.

Este fator foi observado em nossas visitas à Escola, especialmente quando uma professora cuja sala de educação infantil situada próxima à sala de professores e ao corredor de trabalho administrativo-pedagógico, nos deu atenção ao iniciarmos nossas visitas de observação enquanto os demais profissionais não nos deram importância. Observamos que nossa presença não era vista como elemento diferente na rotina escolar. A nosso ver, não despertamos curiosidade porque a presença de estranhos é freqüente no dia-a-dia na Escola. Em outras palavras, a rotatividade de pessoas na Escola é comum, fazendo parte integrante da estruturação organizacional sistêmica e escolar. Esta rotatividade permanente de 
pessoal não afeta negativamente o aprendizado coletivo do grupo, desde que estagiários e professores em mini-contrato fazem parte da dinâmica institucional e grupal. O exemplo tomado a partir das falas dos estagiários pode esclarecer esta dinâmica de grupo e ainda reforça o sentido atribuído ao papel da liderança na organização escolar direcionado a esta particularidade:

A relação com a direção é ótima, participo de reuniões do Conselho. Fiquei antes de vir pra cá numa creche, mas não gostei muito porque lá tem diferença de tratamento com os estagiários; aqui não, todo mundo é tratado igual, pedem opinião, você é escutado.(E2)

O estagiário sente que faz parte da Escola, que é valorizado nas relações com todos que a compõem e também em sua organização, o que permite inferir que as relações interpessoais são flexíveis, não lineares. Em outras palavras, não é o tempo de vínculo, se permanente ou temporário, que necessariamente envolve ou distancia alguem do projeto pedagógico da Escola, mas a clareza da organização escolar de que a alternância de pessoas faz parte de seu projeto pedagógico.

Fazer uma auto-avaliação como monitor é difícil, porque falta preparo com relação à prática; era para a gente ter treinamento para lidar com as crianças na execução dos programas. Eles ensinam como ajudar as crianças a aprender, a não fazer o trabalho pelo aluno, a não tomar a frente do aluno.(E1)

Os estagiários não apenas são respeitados como membros componentes da organização escolar, mas suas opiniões são levadas em consideração internamente. Além disso, a equipe e a própria Secretaria de Educação tem a preocupação de oferecer capacitação apresentando as diretrizes curriculares da rede de ensino aos estagiários. Assim, os princípios pedagógicos do sistema educacional são divulgados, permitindo sua integração no meio escolar, o que legitima a direção institucional tomada, que inclui o pessoal contratado em regime transitório. A própria diretriz, conforme o estagiário, atribui certo sentido emancipatório como conteúdo pedagógico.

Cabe aqui uma ressalva quanto ao modelo de organização democrático. A organização democrática pressupõe, em contraposição à antiga ordem explicitamente burocrática, uma estrutura mais flexível e complexa, transformando o tempo e a organização de trabalho num mosaico que liberta da padronização, ao mesmo tempo em que destitui o trabalhador do controle de seu próprio tempo e organização do trabalho.(SENNETT', 2000).

É assim que, mesmo qualificando estagiários, a estrutura administrativa de funcionamento e contratação de pessoal limita a formação de um grupo de trabalho na Escola que possa dar continuidade e permanência ao projeto 
pedagógico propriamente escolar, demonstrando uma face da racionalidade burocrática-instrumental, mais do que uma estimulação à organização escolar com sentido emancipador, apesar do conteúdo pedagógico divulgado na capacitação da rede escolar. O modelo democrático traz a lógica organizacional do antigo modelo que conserva, através de estratégias institucionais (controle através de procedimentos padronizados), um sentido de subordinação.

Nestes termos, a organização formal/institucional apresenta-se concretamente como fenômeno complexo que ora se apresenta como fator limitante à construção do projeto organizacional, ora abre possibilidades para a sua instituição endógena. Por isso, o tempo é aqui utilizado como um dos indicadores da racionalidade burocrática que ainda permanece na organização escolar democrática. Sua interferência no comportamento valorativo na organização escolar, no entanto, é relativa, visto que esta reflete regras de cooperação e respeito mútuo, indicativos da democratização.

A organização escolar, assim, baseia-se em regras de reciprocidade de ação entre cada sujeito e seus colegas de trabalho e espelha um comportamento cooperativo.

\section{REGRAS VIVIDAS REFLETINDO VALORES CONSTRUIDOS, APESAR DA FALTA DE TEMPO}

As estratégias de produção do modelo organizacional são, como podemos depreender, singulares e sustentam-se entre o instituído e o instituinte, sendo associadas não apenas a um projeto específico, mas também à espontaneidade e, neste sentido, à diversidade. Ressaltamos que o respeito à diversidade é um dos princípios democráticos.

A explicitação da noção de espontaneidade é apresentada num depoimento do corpo técnico-pedagógico:

Professor tem uma coisa espontânea, de participar com idéias, planos, projetos.
Alguns desdenham. É um universo sem homogeneidade. Muitos professores
gostariam de ter tudo igual na sala de aula, mas não dá, tem diferenças!
[E continua explicando o que entende por competência pedagógica:] Tem uma
professora que tem uma prática rasteira, mas tem bons resultados, alfabetiza,
tira o máximo do aluno. Ninguém é o dono do conhecimento, a gente aprende.
Competência pedagógica é ter o retorno do aluno, não é conhecimento, não é
graduação. (CTP)

A presença da crítica incide sobre modelos pedagógicos institucionalizados que nem sempre dão o resultado esperado, apesar do conhecimento de uma base teórica que estabelece para a rede de ensino uma 
determinada linha metodológica. A abordagem de critérios próprios para a construção de um entendimento do trabalho pedagógico na organização escolar é indicativa de um modelo dialógico-crítico. O princípio da diversidade se faz presente e há valorização das idéias, sinônimo de um mínimo necessário de reflexão.

Constatamos que existem regras informais sendo vividas na organização escolar, sem homogeneidade, o que nem sempre representa infração de princípios instituídos, como o direito do aluno aprender (como princípio filosófico-pedagógico proposto pela rede de ensino). A proposição endógena de um trabalho que é eficaz, neste caso, por parte de uma professora, reforça o argumento que desvincula infração normativa e cidadania ativa. A idéia de prática rasteira é associada à imagem da tendência pedagógica tradicional que, quando associada ao bom resultado, configura-se como noção positiva do trabalho desenvolvido. Não necessariamente implica em crítica ao modelo pedagógico instituído (sócioconstrutivismo), nem incorporação do modelo tradicional como regra, mas vinculo ao principio da diversidade de modos do fazer pedagógico, ou melhor, à construção individual do saber fazer, princípio fundamental do próprio sócioconstrutivismo. A interpretação da entrevistada nos traz, portanto, indícios de uma proposição organizacional singular a partir da diversidade de práticas pedagógicas ali veiculadas.

A diretora também faz referências às regras informais:

A construção coletiva movimenta a Escola com uma indisciplina que é normal. Algumas pessoas não conseguem se enquadrar no 'movimento indisciplinado normal' e precisam de tudo certinho, de regras prontas, estabelecidas. Por exemplo, as oficinas foram estabelecidas pelo coletivo; os que não entendem, não só não conseguem trabalhar, mas terminam desarticulando o resto. Não é luta por um espaço, é enquadramento numa realidade móvel, dinâmica. (D)

O entendimento de normalidade da indisciplina vincula-se ao de uma dinâmica difusa, sem forma definida, informal, característica da cultura organizacional da Escola. A indefinição de uma forma específica de disciplina também se articula com a singularidade organizacional. Além disso, a compreensão demonstrada dos que entendem e dos que não entendem a dinâmica própria da Escola reforça o argumento anterior, do respeito ao princípio democrático da diversidade ou pluralidade, respeito às individualidades. Não há um único modelo de disciplina porque a Escola não segue modelos: constrói os seus próprios.

A proposição de modelos singulares aparece também com relação ao papel atribuído ao Conselho Tutelar. A Escola e, mais especificamente, seu "núcleo motor" demonstra certa clareza quanto ao papel auxiliar do Conselho Tutelar como instituição que apóia, mas não determina o que esta deve fazer, 
o que caracteriza a noção de potencial organizacional para a autonomia. A geração de regras internas, apesar das normas do sistema educacional, isenta a organização do caráter de burla e a identifica com a busca de justificativas para situações problemáticas com as quais se defronta.

Exemplo disto foi observado numa situação de final de ano letivo (mês de outubro), quando da chegada de um aluno transferido de outra escola. A diretora explica para a mãe que a Secretaria de Educação não permite por lei, mas afirma que a Escola não pode deixar um aluno sem estudar, como quem diz "o que é que eu posso fazer?". Encaminha a mãe para ir à secretaria da Escola, autorizando a transferência. Esta atitude parece ser conscienciosa, demonstrando haver algum sentido no trabalho escolar, bem como uma filosofia que norteia a pratica pedagógico-administrativa, que leva a Escola a aceitar crianças, seja como e quando for, desde que é regida por um conjunto de princípios valorativos, dentre os quais, o do direito à cidadania, que inclui acesso à Escola, apesar da regra sistêmica. Assim, o valor que fundamenta a ação - aceitação de transferência em período ilegal - supera e justifica a fraude.

$\mathrm{Ha}$ ainda mais um exemplo que demonstra o sistema normativo informal da Escola na fala do corpo técnico - pedagógico, quando apresenta a atitude de uma professora em relação ao comportamento indisciplinado da turma de alunos:

Uma professora chegou na sala e colocou os pés em cima da mesa. O aluno perguntou: o que é isso, professora? Aí ela disse: Vocês não colocam assim? Por que eu não posso? (CTP)

A entrevistada esclarece que a Escola procura falar na linguagem das crianças, brincando, mas enfatizando uma relação de respeito, ao mesmo tempo em que afirma que as crianças não devem voltar para casa por mau comportamento, mas devem ser atendidas nas suas necessidades, sendo encaminhadas eventualmente para atividades alternativas e chamando os pais quando necessário, visando sua educação. Ela continua, explicando:

Eu não posso querer moldar os alunos a terem o comportamento que eu cobro dos meus filhos em casa. Até porque, às vezes, ele [o aluno] é até ridicularizado em casa com esse comportamento. A gente pode melhorar, mas mudar tudo não dá. Muitos meninos presenciam inclusive relacionamento sexual. Não posso querer moldar, mas ele tem que saber que a Escola é uma instituição, que tem regras que eles devem seguir. (CTP)

O exemplo traz a articulação de um conjunto de argumentos para justificar o sistema normativo informal da Escola, baseado em princípios 
valorativos como o respeito e a educação numa perspectiva abrangente. O comportamento descrito da professora que coloca os pés em cima da mesa serve para a entrevistada mostrar que são aceitos procedimentos não protocolares como mecanismo de ajuste em meio às condutas consideradas regulares para o comportamento docente.

Esta construção viva e ativa é percebida por parte dos que fazem a Escola, ainda que nem todos compartilhem os mesmos modelos de ação, nem tampouco todos os princípios valorativos com a mesma clareza. De fato, os diversos segmentos apresentam diferentes interpretações para a dinâmica escolar, em seus variados aspectos. Assim, uma mãe refere-se à inteligência das crianças apontando o sentido do trabalho escolar: "Não sei dizer sobre o ensino. Algumas (crianças) aprendem. As mais rebeldes são bem inteligentes, muito mal criadas, mas inteligentes." (M)

A potencialidade intelectual dos alunos é valorizada da mesma forma que a potencialidade docente de ajuste às situações. Colocar os pés em cima da mesa foi interpretado como uma resposta docente ao comportamento dos alunos e não necessariamente desrespeito, bem como a rebeldia discente foi interpretada em associação com inteligência ou atividade, não desrespeito. O entendimento sobre os comportamentos não convencionais denota valor afirmativo.

Além disso, a distinção que a mãe faz quanto ao conflito inteligência versus comportamento indisciplinado demonstra seu potencial para opinar nas questões educacionais e escolares. Paradoxalmente, entretanto, extravasa o sentimento de baixo auto-referencial da comunidade para opinar nestas questões. O ciclo vicioso negativo que se explicita na baixa auto-estima da comunidade que "sabe de seus limites" é contrabalançado com a possibilidade de vislumbrar críticas argumentadas por parte da comunidade, que espera alternativas estimuladoras para o incentivo à inteligência de seus filhos.

O exemplo da fala desta mãe retrata uma outra face do perfil instituinte da organização, não como proposição de regras, mas configurada como crítica argumentada que se torna exigência atitudinal alternativa da Escola, essência do movimento instituinte.

Há também alusão explícita ao conjunto de valores da organização escolar e da necessidade de discuti-los e sistematizá-los, conforme a expressão de um professor num momento de reunião do Conselho Escolar, para facilitar a dinâmica da ação organizacional em sintonia cooperativa:

Eu queria falar dos valores, queria criar uma comissão para ir construindo o regimento interno: que valores que a Escola pode adotar como valores para o regimento da Escola? Parece que a própria prefeitura ainda não sabe qual é a tarefa, como vai ser o controle social da educação. Eu tenho ouvido falar de 
indisciplina e acho que a gente poderia começar um processo de discussão para já valer como referência nossa, mais consistente, mesmo antes do regimento. $(\mathrm{P})$

Os exemplos retratam o processo de construção de um sistema normativo interno, no caminho da autonomia, bem como a independência de determinações da rede municipal de ensino, em função de necessidades surgidas no interior da organização escolar. Observa-se uma forma de participação espontânea construindo a autonomia e buscando instituir uma identidade de grupo. Naturalmente que o processo não ocorre de forma homogênea por parte de todos que fazem a Escola e, portanto, encontramos situações de burla de regras consensuais, que entendemos ser o reflexo de ausência ou insuficiência de significado para as regras existentes.

Esta construção é difusa, processual e constitui-se como um amadurecimento do coletivo escolar, ora via conflito, ora via indiferença aparente. Reforçamos a afirmação anterior de que não se segue à risca um padrão normativo instituído porque a Escola constrói os seus próprios modelos de ação. Seu movimento organizacional reflete, portanto, uma interação entre as regras do sistema educacional e a proposição de regras endógenas, sejam formais, nãoformais ou informais. A produção de modelos de comportamentos alternativos é característica e concretização do princípio da autonomia na Escola.

Isso é possível porque os padrões de organização instituídos pelo sistema educacional consentem, via frestas inerentes ao próprio modelo democrático adotado, a intervenção autônoma dos sujeitos. Neste sentido, Lima (2002) explica que o exercício da autonomia possibilita a construção de modelos de gestão, num sentido plural, diversificado, em formatos variáveis em cada escola.

A natureza e o âmbito dos modelos decretados serão profundamente alterados (e estreitados), insistindo mais nos grandes princípios e perspectivas gerais, bem como nas formas de responsabilização dos órgãos e atores escolares, assim abrindo possibilidades de uma estruturação mais livre a nível escolar, alargando e aprofundando a tipologia e o alcance das regras e das decisões.(op.cit.p.52)

Até mesmo os discursos críticos, ainda que acompanhados de práticas que denotam passividade, não significam simples ausência, mas resistência ao modelo democrático regulador. Aliás, a própria negação constitui-se como um movimento de afirmação, típico da reflexão filosófica.

Há, sim, uma ética em construção, permeada por diversas éticas. Estas, denotam indicadores diferentes para a organização escolar, para o estabelecimento de regras em seu interior, bem como para a sua concretização, inclusive para a participação e proposição de novas regras. 
O modelo organizacional adotado pelo sistema educacional inclui a autonomia que se materializa na medida em que o exercício da autonomia define os próprios modelos de gestão nas escolas.

Nestes termos, compreendemos que o modelo de organização da Escola aproveita os espaços disponibilizados pelo sistema escolar, ultrapassando os limites dos modelos burocrático e democrático a partir da própria visão que os sujeitos têm da organização, o que garante sua mobilização instituinte.

\section{O TEMPO E A ORGANIZAÇÃO ESCOLAR: ENTRE A AUTONOMIA E A REGULAÇÃO}

Ao abordarmos o conflito existente entre a regulamentação educacional e as possibilidades de sua implementação por parte das escolas, observamos um comportamento organizacional e valorativo que revela o próprio projeto políticopedagógico da Escola que emerge como mediação entre as determinações formais do sistema e a autonomia da Escola. Os limites e possibilidades existentes a partir do conflito aparecem sob formato difuso como problemas da organização escolar, o que atribuimos às diferentes lógicas ou racionalidades presentes no sistema educacional.

Do ponto de vista do sistema, a ação instrumental organiza meios que julga adequados segundo critérios de um controle eficiente da realidade, enquanto que do ponto de vista da escola, a ação estratégica varia conforme uma valoração de possíveis alternativas de comportamento, o que ocorre com o auxílio de princípios e valores. $\mathrm{Na}$ escola, as normas são fundadas e validadas a partir da intersubjetividade do acordo. As decisões são tomadas em conformidade com certa racionalidade organizacional, conduzindo à normatização institucional.

O exemplo apresentado referente à falta de tempo indica certo limite, mas não inibe o exercício do potencial crítico-argumentativo, de forma que é possível, apesar do pouco tempo, a realização de um trabalho integrado da equipe pedagógica.

A rotatividade permanente de pessoal é outro exemplo de como os limites burocrático-formais incidem sobre a organização da escola, mas não necessariamente afetam negativamente o aprendizado coletivo do grupo, podendo ser incorporados como parte da dinâmica institucional e grupal.

A escola é observada, portanto, como sendo regida por um conjunto de princípios valorativos construidos em seu cotidiano, apesar das regras sistêmicas que fundamentam ações que eventualmente permitem superar limites e justificar alternativas encontradas via burla das regras determinadas pela rede de ensino 
sem, necessariamente, infringir princípios basilares da gestão democrática da educação.

Não queremos, com estas considerações, apresentar uma visão ingênua de que a escola é a responsável única por seu sucesso a partir de dentro, como se estivéssemos esquecendo que o complexo contexto sócio-politicocultural discriminatório e excludente vem gerando, historicamente, implicações nefastas no que tange ao sistema educacional. Queremos, no entanto, afirmar a responsabilidade da escola em gerar a partir de dentro algumas condições de gestão de seus processos que sejam afirmativas para o desenvolvimento de uma formação cidadã, ao invés de culpabilizar o Estado - como o Outro - por todos os males que afligem a escola hoje.

Compreendemos, por fim, que o processo de construção de um sistema normativo interno, no caminho da autonomia, com relativa independência das determinações da rede municipal de ensino é possível quando os padrões de organização instituídos pelo sistema educacional consentem, via frestas inerentes ao próprio modelo democrático adotado, a intervenção autônoma dos sujeitos. Assim, os conflitos presentes na relação existente entre a regulação e a autonomia outorgada são parte inerente a qualquer sistema educacional, sendo que o modelo organizacional adotado pelo sistema educacional brasileiro inclui a autonomia que pode vir a se materializar na medida em que o exercício da autonomia vier a definir modelos de gestão singulares nas escolas, o que pode ser efetivado a partir do desenvolvimento de uma racionalidade crítico-argumentativa.

\section{REFERÊNCIAS}

BOTLER, Alice. A escola como organização comunicativa. Recife: UFPE, 2004. Tese de Doutorado em Sociologia.

CORTINA, Adela. Razón comunicativa y responsabilidad solidaria. Salamanca: Ediciones Sígueme, 1988.

DEROUET, Jean-Louis. Autonomie et responsabilité des établissements scolaires en France. Revista Colóquio Educação e Sociedade n.4, out/1998. Lisboa: Fundação Calouste Gulbenkian,p.19-31, 1998.

ESTÊVÃO, Carlos. Redescobrir a escola privada portuguesa como organização. Braga, Portugal: UMINHO, 1998.

FRIEDBERG, Erhard. O poder e a regra: dinâmicas da ação organizada. Lisboa: Instituto Piaget, 1993. 
HABERMAS, Jürgen .Técnica e ciência como 'ideologia'. Lisboa: Edições 70 (tradução de Artur Morão), 1968.

Teoría de la acción comunicativa I. Racionalidad de la acción y racionalización social. Madrid: Taurus, 1987.

LIMA, Licínio. Modelos organizacionais de escola: perspectivas analíticas, teorias administrativas e o estudo da ação. In: MACHADO, Lourdes e FERREIRA, Naura Syria (org.) Política e gestão da educação: dois olhares. Rio de Janeiro: DP\&A. pp. 33-35, 2002.

NÓVOA, Antonio. As organizações escolares em análise. Portugal: Dom Quixote 1992.

PIZZI, Jovino. Ética do discurso: a racionalidade ético-comunicativa. Porto Alegre: EDIPUCRS, 1994.

SANTOS, Boaventura. Pela mão de Alice: o social e o político na pósmodernidade. 8. ed. São Paulo: Cortez, 2001.

SENNETT, Richard. A corrosão do caráter. Rio de Janeiro: Record, 2000.

VIANNA, Heraldo Marelin. Pesquisa em Educação - a observação. Brasília: Plano Editora, 2003.

ALICE MIRIAM HAPP BOTLER é doutora em Sociologia pela UFPE e realizou estágio de Pós-doutorado na Ontario Institute for Studies in Education na University of Toronto (2010). É docente da Universidade Federal de Pernambuco onde atua no curso de Pedagogia, no Programa de Pós-graduação em Educação e coordena o PIBID Institucional. E-mail: alicebotler@gmail.com

Recebido em janeiro de 2015 Aprovado em fevereiro de 2015 